\title{
Using VISIR in a Large Undergraduate Course: Preliminary Assessment Results
}

\author{
doi:10.3991/ijep.v1i1.1589
}

\author{
Gustavo R. Alves ${ }^{1}$, M. A. Marques ${ }^{1}$, C. Viegas ${ }^{1}$, M. C. Costa Lobo ${ }^{1}$, R. G. Barral ${ }^{1}$, R. J. Couto ${ }^{1}$, F. L. Jacob ${ }^{1}$, \\ C. A. $\operatorname{Ramos}^{1}$, G. M. Vilão ${ }^{1}$, D. S. Covita ${ }^{1}$, Joaquim Alves ${ }^{1}$, P. S. Guimarães ${ }^{1}$, Ingvar Gustavsson ${ }^{2}$ \\ ${ }^{1}$ IPP - Polytechnic Institute of Porto, Porto, Portugal \\ ${ }^{2}$ BTH - Blekinge Institute of Technology, Karlskrona, Sweden
}

\begin{abstract}
The use of remote labs in undergraduate courses has been reported in literature several times since the mid 90's. Nevertheless, very few articles present results about the learning gains obtained by students using them, especially with a large number of students, thus suggesting a lack of data concerning their pedagogical effectiveness. This paper addresses such a gap by presenting some preliminary results concerning the use of a remote laboratory, known as VISIR, in a large undergraduate course on Applied Physics, with over 500 students enrolled.
\end{abstract}

Index terms - remote laboratories, weblabs, learning assessment, engineering education.

\section{INTRODUCTION}

In the engineering curriculum, remote labs are becoming a popular learning tool. Based on computers and the Internet we come to new types of laboratories which offer greater flexibility and allow access by more students within a given time frame while reducing the total acquisition, operating and maintenance costs.

As education and technology merge, the opportunities for teaching and learning expand even more. However, the very rapid rate of change in the fields of technology poses special problems for academic institutions, specifically for the engineering disciplines. There is of course a continual need to update and augment the content of lecture courses to keep pace with this change, but it is in the area of engineering education and experimental work that major concerns arise. The central problem still remains the same: providing for students meaningful and relevant practical experiences while being limited by very finite resources in the provision of laboratory hardware and infrastructure. One solution to this problem is to use computer-based techniques to interface the students with the physical world, with suitable front end design to provide increasing sophistication and increased flexibility. Many academic courses that teach engineering subjects have already begun incorporating computer-based educational tools for student use, either in the lectures or in the laboratory practices or both. Furthermore, information and experience sharing are becoming increasingly critical to educational institutions as well as to practicing engineers, mainly driven by the advancements in computer technology and the Internet. The advantages of these laboratories and the different deployments have been analyzed many times [1, $2,3]$. Since 2000 , a huge number of remote laboratories have been designed, implemented and set up over the world. [1, 2, 3, 4, 5]. Papers and books about remote labs focusing on their advantages/disadvantages, state of art, technologies, and didactic have been published. Most of these works are focused on the technology and only few articles are focused on the didactic utility of remote labs as a didactic tool.

When technology-intensive teaching tools become widely available, the traditional roles of the university lecturers will change from pure classroom-based teaching to one of consultation, advice and direction giving. However, it is believed that the technology-based course will not eliminate the educators; instead it will change the type of activities the educators carry out. In the technologybased teaching/learning practice, the major activities of the lecturers may include preparation of the software packages, adopting new concepts and new teaching practices, modifying existing materials to suit the changes introduced by the latest version of the multimedia tools, and above all these they can spend time to continuously evaluating the teaching/learning outcomes.

The roles of teachers and students are changing, and there are undoubtedly ways of learning not yet discovered. However, the computer and software technology may provide a significant help to identify the problems, to present solutions and life-long learning. It is clear that the computer-based educational technology has reached the point where many major improvements can be made, and significant cost reductions can be achieved, specifically in the area of engineering education. In engineering, the fullcourse (lecture, laboratory component, etc.) may replace the existing lecture-based courses, and the virtual instruments may provide a highly interactive user interface and advanced analysis facilities that were not deliverable in the conventional methods.

The proper use of techniques and methodologies is critical in any technology intensive teaching/learning development system. In addition, it should be ensured that the designed work keeps up with the curriculum review and update, and the laboratory work should be relevant to the material taught in lectures. These may require continuous update of the material, which may change the role of the educator. Furthermore, the Internet has the potential to provide a highly supporting learning environment. It can enable students to access without time and distance limitations, and can allow them to use expensive laboratory experiments to which they usually have no access. However, it is not sufficient to expect that existing tools and techniques will translate simply and quickly. They have to be transformed in ways that learners and educators perceive to be useful and effective. 
One reason for the limited research on instructional laboratories may be a lack of consensus on the basic objectives of the laboratory experience [1]. While there seems to be a general agreement that laboratories are necessary, little has been said about what they are expected to accomplish. In most papers about laboratories, no course objectives or outcomes are listed, even though it is not unusual for the author to state in the conclusion that the objectives of the course were met. An accepted set of fundamental objectives for laboratories would help engineering educators focus their efforts and evaluate the effectiveness of laboratory experiences.

In this paper we address the role of the laboratory environment while conducting experiments for perceiving some fundamental concepts of electrical circuits, namely the behavior of simple circuits built with resistors, coils and capacitors, when powered with Direct Current (DC) and Alternate Current (AC) sources. We have used a set of tools for assessing the learning gains obtained by students enrolled in a large Physics course of an undergraduate degree on Informatics Engineering. Students were divided into two natural groups: one attending both hands-on and remote lab classes and another simply using the remote lab. Preliminary results indicate that both students groups presented learning gains, which suggests the remote lab used to be a good learning tool for developing experimental skills in the taught topic. The rest of this paper is organized as follows: section II describes the assessment scenario, namely the remote lab environment, i.e. VISIR (Virtual Instrument Systems in Reality), the course curriculum and structure, and the assessment methodology; section III presents the preliminary assessment results, organized in two categories, namely the integration of VISIR in the target course and the students' results; finally, section IV concludes the paper.

\section{SCENARIO AND Methodology}

\section{A. The VISIR system}

VISIR is an open remote lab dedicated to experiments on electrical and electronic circuits, acquired by and installed at the Polytechnic Institute of Porto - School of Engineering (IPP/ISEP), Portugal, in July 2010. Its architecture and characteristics are well described in several articles, namely in [6] and [7]. In this paper, we concentrate on describing the actions done by persons using this system under three different roles (administrator, teacher, and student), to emphasize its simplicity, minimal learning curve, and reduced institutional impact, namely on integration and maintenance aspects.

Fig. 1 illustrates the three main components used at ISEP to store and manage institutional data (Portal), pedagogic contents (Moodle), and, most recently, to provide remote experiments (VISIR). All components are accessed through a secure connection (https), although not necessarily sharing the same certificate. All these components have an administrator, which, again, may not be the same for all. When starting a new semester, teachers have access to structured information on both Portal and Moodle, i.e. they will have access to the course(s) they will be lecturing, and all the students enrolled in those courses will also have access to teaching \& learning materials made available by teachers. The login credentials used by teachers and students to access both Portal and Moodle are the same, although there is no direct path be-

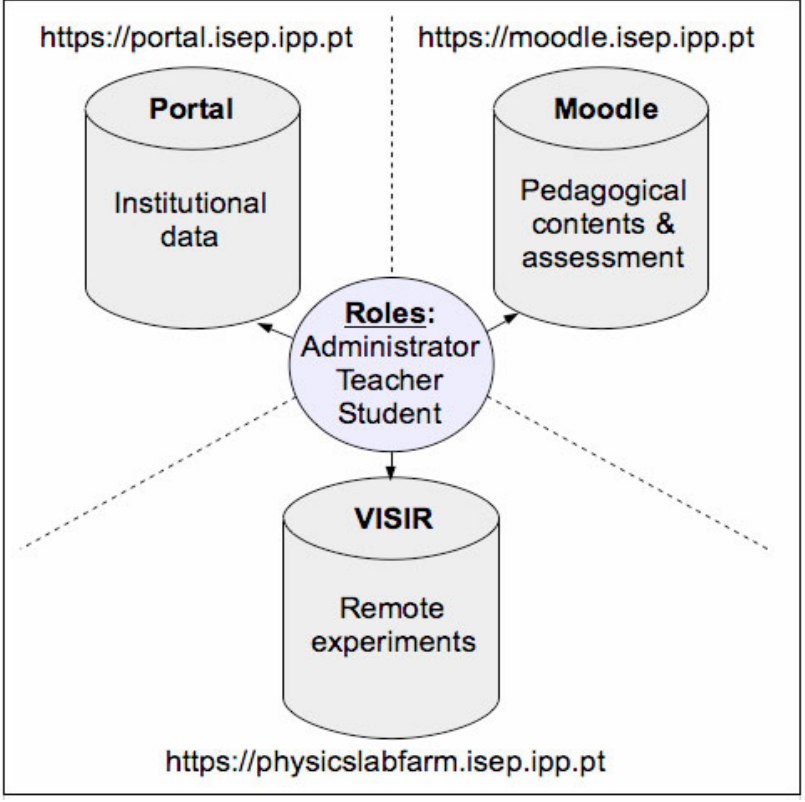

Figure 1. Sites used for institutional and teaching and learning purposes at ISEP

tween these two components, i.e. if individuals log into Portal and later need to check something on Moodle, they will need to reintroduce their login credentials. The addition of a new third component (VISIR) implied some organizational rearrangement, namely on how to manage teachers and students access to the remote lab, and on how to manage the courses created on VISIR. The next paragraphs will therefore describe the actions done by administrators, teachers, and students, in VISIR, following a sequential timeline.

Administrators start by creating a given course. They then add (i) the responsible for the course (a given teacher), (ii) other teachers / instructors (typically, courses with hundreds of students have a team of several teachers), and finally (iii) the students enrolled on that course. Presently, this last action simply implies copying \& pasting the list of e-mails of those students enrolled in the same course, into VISIR, as depicted in Fig. 2. In conclusion, although VISIR is a fairly new component, it implied a reduced extra effort into current ISEP administrators' tasks. This fact is thought to be crucial to convince institutional managers that remote labs do not represent an additional cost, in terms of workload, to the Communications and Informatics Service [8].

Once the course is created, the teacher responsible for it is able to add new experiments according to the course practical component. This follows a procedure described in [9], where the teacher needs to be aware of the components physically available in the VISIR matrix, or, if not available, indicate his/her needs to the lab technician, responsible for configuring and updating the matrix. Assuming that the components are available in the matrix and that their images are also available in the list of components depicted by the VISIR interface, in teacher mode, the teacher may then add a new experiment to its course and then add a direct link to it, into the corresponding Moodle course page. These actions are illustrated in Fig. 3.

Students access VISIR either through the link provided in the Moodle course page, where in each case they will 
be required to enter their login credentials and after that will be directed to the related experiment or, through the VISIR URL (see Fig. 1). In this last situation, students will also have to indicate their login credentials and then will be directed to a page that contains a navigation menu on the left side, where students can see the courses they are enrolled in. Selecting a particular course will open a page displaying the list of experiments currently available on that course. Students may then select one experiment, ending up on the same page they would get if following the direct link provided in Moodle. In both situations, VISIR will track the students' access by incrementing a counter indicating the number of sessions done by each student, as depicted in Fig. 4. This figure illustrates the administrators' and teachers' view of the list of users enrolled on a particular course. Administrators may use this page to access a user profile or to simply remove him/her from the course by selecting the cross on the page right side (see Fig. 4).

The number of sessions done by each user and the indication of whether a user account has been (or not) enabled and/or activated is also displayed. Students activate their accounts by indicating their e-mail addresses on the VISIR login window and then clicking on the "Activate account" button, which causes the VISIR system to generate and send messages to the provided e-mail addresses, containing the students' passwords. An activated account with zero accesses indicates a peculiar situation where a student has accessed VISIR to activate his/her own account but then performed no remote experiment at all.

\section{B. Scenario description}

ISEP is an engineering school offering a large number of bachelor degrees in areas like Electronics, Informatics, Chemistry, Mechanics, Medical Instrumentation, Metrology, Civil and Geotechnical Engineering. Many of these degrees are complemented by a variety of Master degrees and Post-graduate courses. Since VISIR is a system constructed on top of computer-based resources, the target environment chosen for our experiment was the Applied Physics course of the Informatics degree, since these students naturally like this type of tools and resources. The Informatics degree is one of the degrees with a large number of students, over 220 new students enrolling every year. This is still one of the areas that keeps attracting an increasing number of students. Like all engineering degrees at ISEP, this is also a 3-year degree where, in the $1^{\text {st }}$ year, students acquire mathematical, programming and lab work skills. Applied Physics is only taught in the $1^{\text {st }}$ semester of the $2^{\text {nd }}$ year. It is only at this time students have contact with physics at university. Our study was developed over this period of time, with students enrolled in the course.

Applied Physics in the Informatics degree has a duration of 12 weeks with three types of weekly classes: $2 \mathrm{hrs}$ of lab work, $1 \frac{1}{2} \mathrm{hrs}$ of problem solving and $1 \mathrm{hr}$ of theoretical classes. The course program starts with units and dimensions, followed by electricity, waves and heat transfer, therefore covering a large variety of topics in a rather short period. Students are assessed by two evaluation components: (i) by their lab work performance, which has an overall weight of $40 \%$ and (ii) by final examination with an overall weight of $60 \%$.

For the purpose of our study, the 561 students enrolled were divided in two groups accordingly to the conditions

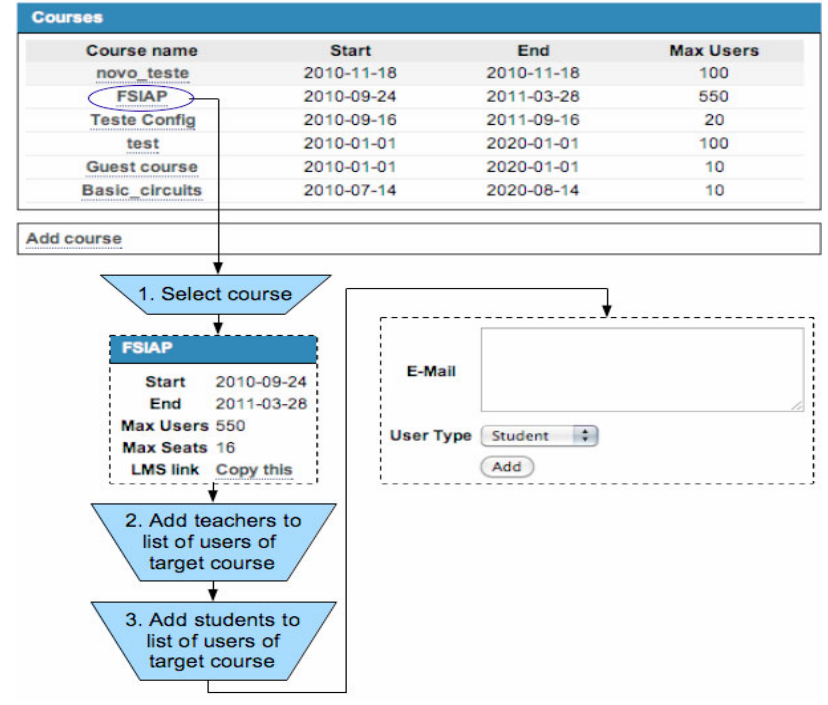

Figure 2. Adding a list of users to a given course, in VISIR

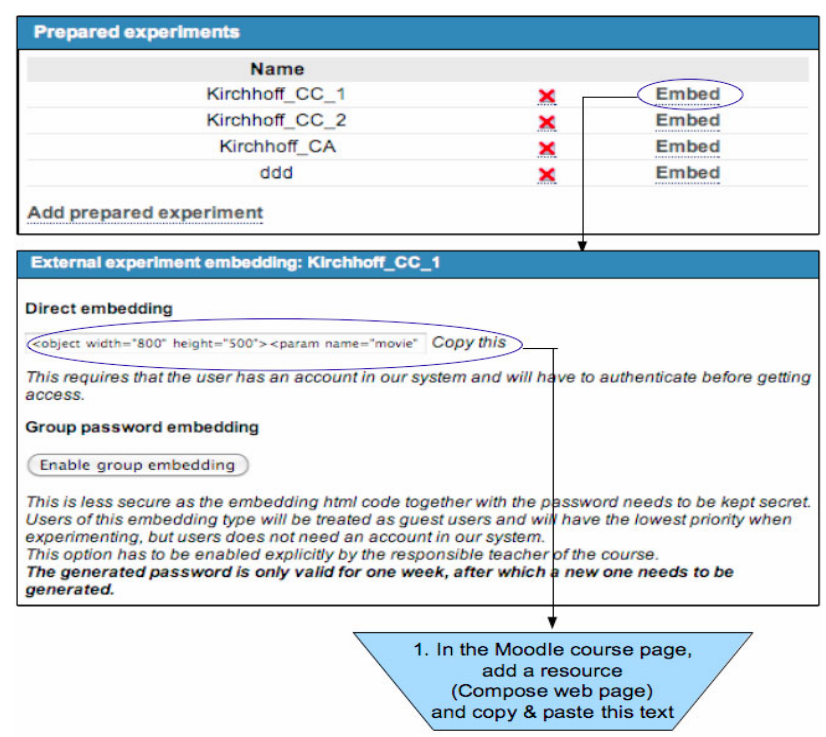

Figure 3. Embedding a direct link in Moodle, to a remote experiment in VISIR

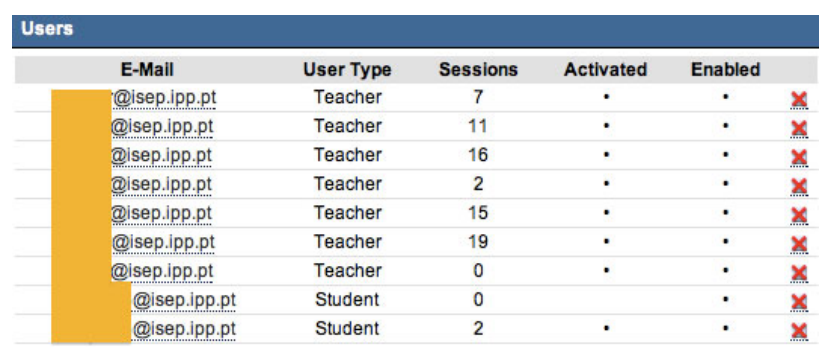

Figure 4. VISIR users tracking information system

they were attending the course. Group A, with a total of 288 students, corresponds to those students performing hands-on lab work during some of the laboratory classes, while group B, with 273 students, develops a comparative analysis with values taken from the remote system and hypothetic ones in those same classes. Since every student has to be assessed by the same two components just described, it happens that group B students already have a lab work mark from previous years. A valid condition for all the students is to accomplish a minimum mark of 8 , out 
of 20, in the final examination to be considered for course approval. Finally, the course was organized in 15 classrooms corresponding to group A and 4 classrooms for group B. Since students from group A are expected to mount real circuits, in each classroom they are organized in 6 groups of 3-4 students each, with a maximum of 24 students per classroom.

Since VISIR is a remote system targeting the acquisition of experimental skills with electrical circuits, students were using it during the time-period the topic on electricity was being presented and studied in classes, i.e., from September, $27^{\text {th }}$ to November, $1^{\text {st }}$, in a total of 6 weeks, as shown in TABLE I.

In the first week, students were introduced to electricity in theoretical classes, where concepts like resistors associations and Ohm's and Kirchhoff's laws for DC circuits were taught. At the same time, in the first laboratory class, VISIR was introduced by teachers, starting with a small presentation of the VISIR interface and explanation about its usage. After this introduction, teachers asked their students to try for themselves, in order to accomplish the designed circuit of the laboratory task. Every student was provided with a lab guide describing the experimental procedure for a DC circuit, which apart from being implemented, they had to take measurements from. Only group A students had hands-on lab classes during the week after, specifically to mount the same circuit (for real), as depicted in TABLE I. During the following two weeks, this procedure was repeated for an AC circuit, with the help of the corresponding lab guide. $24 \mathrm{hrs}$ after each real-circuit implementation class, every group had to hand-over a lab report, where they had to include handson circuit measurements and VISIR measurements. During week 5 , every student, individually, had to write an extended report on one of the experiments done with the measurements previously taken. This was done in order to distinguish between students of the same group and since every group implemented two experiments. This procedure was only applied to group A students. Group B students were similarly introduced to VISIR in the same week as previously described. Nevertheless, and as stated before, while group A was doing hands-on lab work group $\mathrm{B}$ was developing a comparative analysis on the same two circuits, DC and AC, using components' nominal values and values obtained from measurements in VISIR.

Apart from being used to encourage students to gain confidence and practice in the matter, VISIR was also used by teachers in week 5 , to demonstrate the behavior of passive RC and RL filters as a practical application of the circuits previously mounted.

\section{Assessement Methodology}

Our goal was to assess the use of VISIR in a large undergraduate course with two natural groups of students due to the course constraints: group A - students who necessarily had laboratory classes, and group B - students who already attended those classes in previous years (but got no course approval) and only had recitation classes (with a larger number of students). This implementation was complementary to the real laboratory classes for group A and the only laboratory contact for group B.

Apart from the five teachers involved in lecturing this course, two other teachers handled the system coordination. Our methodology targeted the acquisition of a broad
TABLE I.

LABORATORY CLASSES PLAN FOR TOPIC ON ELECTRICITY.

\begin{tabular}{|c|c|c|}
\hline \multirow{2}{*}{ Weeks } & \multicolumn{2}{|c|}{ Organization of topic electricity for lab classes } \\
\hline & Group $A$ & Group B \\
\hline $\begin{array}{l}\text { Week } 1 \\
27 / 9\end{array}$ & \multicolumn{2}{|c|}{$\begin{array}{l}\text { Introduction to VISIR. Taking measurements in remote sys- } \\
\text { tem for a DC experiment described in the lab guide. }\end{array}$} \\
\hline $\begin{array}{l}\text { Week } 2 \\
4 / 10\end{array}$ & $\begin{array}{l}\text { Real DC circuit mounting and } \\
\text { making measurements. } \\
24 \mathrm{~h} \text { to hand-over the group lab } \\
\text { report. }\end{array}$ & $\begin{array}{l}\text { Comparative DC analysis } \\
\text { with values from previous } \\
\text { class and components nomi- } \\
\text { nal values. }\end{array}$ \\
\hline $\begin{array}{l}\text { Week } 3 \\
11 / 10 \\
\end{array}$ & \multicolumn{2}{|c|}{$\begin{array}{l}\text { Introduction to VISIR. Taking measurements in remote sys- } \\
\text { tem for an AC experiment described in the lab guide. }\end{array}$} \\
\hline $\begin{array}{l}\text { Week } 4 \\
18 / 10\end{array}$ & $\begin{array}{l}\text { Real AC circuit mounting and } \\
\text { making measurements. } 24 \mathrm{~h} \text { to } \\
\text { hand-over the group lab report. }\end{array}$ & $\begin{array}{l}\text { Comparative AC analysis } \\
\text { with values from previous } \\
\text { class and components nomi- } \\
\text { nal values. }\end{array}$ \\
\hline $\begin{array}{l}\text { Week } 5 \\
25 / 10\end{array}$ & $\begin{array}{l}\text { Individual lab report related to } \\
\text { one of the two experiments done. }\end{array}$ & $\begin{array}{l}\text { Teachers use VISIR to } \\
\text { demonstrate previous AC } \\
\text { circuit as a passive filter. }\end{array}$ \\
\hline $\begin{array}{l}\text { Week } 6 \\
1 / 11\end{array}$ & \multicolumn{2}{|c|}{ 1st partial examination related to this topic. (a) } \\
\hline
\end{tabular}

data collection, enabling a large perspective of this implementation. These data not only regards students' knowledge and competency gain in this subject, but also students' usage of VISIR and students and teachers perceptions along the course.

1. VISIR Usage: Teachers and students usage of the system was registered and allowed us to analyze the total amount of sessions run by each student and the global long term (during the six weeks) frequency of usage.

2. Teachers Perceptions: All teachers involved in the course were interviewed and shared their experience about their real practice with VISIR. Some of them, who had past experience lecturing this course, compared some of the characteristics.

3. Knowledge and Competence Assessment: The knowledge and competence questionnaire was constructed by the course head-teacher in conjunction with other teachers/researchers and meant to assess some of the most significant issues of the taught subject. Some of the questions were addressed to directly infer the common knowledge of the students (questions 1 and 2); other questions meant to infer some laboratory competences development (questions 3 and 4); we identified a last set of questions (questions 5, 7 and 8) which was more specific to the characterization of DC and AC circuits. The other two questions $(6,9)$ were procedural, about parallel and series components in a circuit. All teachers delivered those questionnaires in class, on paper, before and after the lectured subject. In order to allow us to compare results for each student, these questionnaires were not anonymous. An explanation of its goals (simply for research purposes) was made by every teacher. Even though the questions were the same in the pre test and post test, their order was changed to avoid memorization.

4. Students Perceptions: All students were subject to a second questionnaire (based on some literature with similar purpose [7], [10], [11]) which meant to assess students' satisfaction and their perception of learning outcomes using VISIR. This questionnaire was done 
anonymously, accessing a Google page in a class, at the end of the course. In addition to this large inquiry, some students of each teacher's class were interviewed in order to reach a more personal view of the class implementation of VISIR and to better understand students' autonomous usage of the system. These students were chosen because of their higher number of sessions run at VISIR, a more significant gain or exactly the opposite.

5. Course Results: Preliminary results included the laboratory reports assessment.

\section{Preliminary Assessment Results}

We organized our preliminary results into two categories: the first one concerns the implementation of the system in a large course, including the report of how it was used, the encountered problems, the usage along the process and also the teachers' point of view about the VISIR integration in the course; the second part concerns the students' results while using this system, their competence and knowledge developments, as well as their own perception of its utility and learning improvement.

\section{A. On VISIR Course Integration}

\section{1) VISIR Usage}

Using the information available in the VISIR users activity tracking system (Fig. 5), we analyzed the total number of accesses, the number of activated accounts, and the number of daily accesses of both students (groups A \& B) and teachers. This information was recorded nominally (i.e. including the user id), every two days, from Sep. $28^{\text {th }}$ till Nov. $7^{\text {th }}$. Considering the course numbers presented in section II-B, a preliminary appreciation of the charts reveals the following:

There is a considerable number (40\%) of students that did not activate their accounts in VISIR. This may be explained by the fact only one student per workgroup (in group A) had to access VISIR to obtain the needed measurements and that, in group B, only few students had access to a computer to connect to VISIR.

The number of activated accounts has a daily growth, suggesting that students pass the word about VISIR and its benefits, although simple curiosity may also explain this phenomenon.

Fig. 5 (top) indicates the accumulated number of students accesses in weeks $1 \& 2$ (DC circuits) and weeks 3 \& 4 (AC circuits), to be roughly the same, i.e. circa 420 compared to approximately 430 , respectively. In week 5 , where students from group A just had to do an individual report, there was a considerable reduction in the number of accesses, i.e. only 80 accesses, which represents nearly $20 \%$ of the accumulated number of accesses in each of the two previous periods (weeks $1 \& 2$, and weeks $3 \& 4$ ).

Weeks $1 \& 3$, where teachers had to demonstrate the usage of VISIR for DC and AC circuits, respectively, are clearly visible in Fig. 8 (bottom). Again, the demonstration in week 5 for students in group B is also visible, considering the almost absence of teachers' accesses in weeks 4 and 6 , where teachers were not supposed to use the system, according to the information presented in TABLE I.

Not many students have used VISIR outside real classes, i.e. typically during weekends. This derives from an examination of the chart depicted in Fig. 6, where the
TABLE II.

VISIR ACCESSES SORTED BY INTERVALS

\begin{tabular}{|c|c|c|}
\hline & Number & Percentage \\
\hline 0 & $\mathbf{3 4}$ & $\mathbf{1 0 \%}$ \\
\hline $1-4$ & $\mathbf{2 2 8}$ & $\mathbf{6 8 \%}$ \\
\hline $5-8$ & $\mathbf{6 0}$ & $\mathbf{1 8 \%}$ \\
\hline $9-15$ & $\mathbf{1 2}$ & $\mathbf{4 \%}$ \\
\hline Total & 334 & $100 \%$ \\
\hline
\end{tabular}
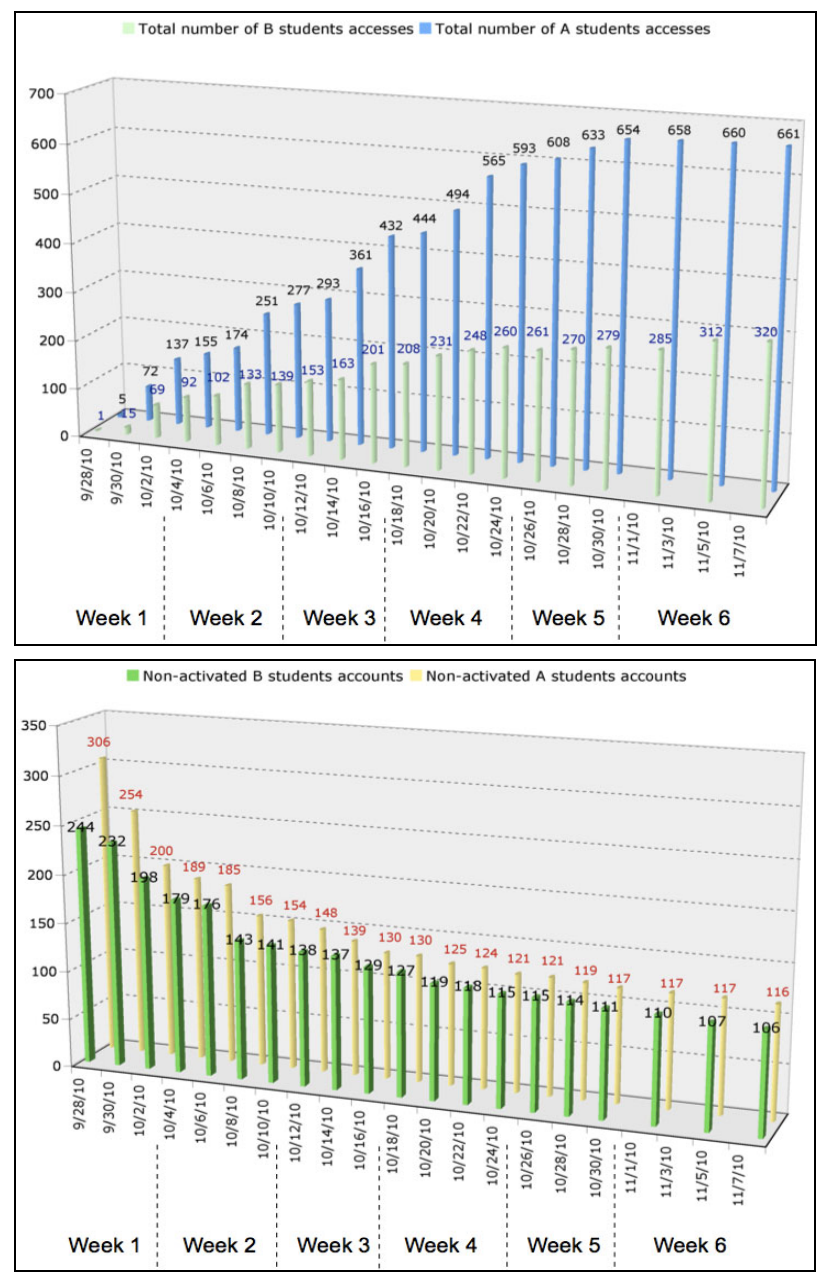

Figure 5. Chart with VISIR access data, divided by groups A and B, including total number of accesses (top) and non-activated accounts (bottom)

2-days number of accesses counted on Sundays or Mondays is always lower than in other weekdays. The gap from the last Saturday to the last Tuesday comes from an accidental episode where the system was down due to a power failure, during Sunday and Monday (an holiday, $1^{\text {st }}$ November).

The number of accesses in week 6 , where students had a $1^{\text {st }}$ partial examination related to this topic (see TABLE I, i.e. they did not have to use VISIR), is purely residual, with only 40 accesses, i.e. $10 \%$ of either the weeks $1 \& 2$ period or weeks $3 \& 4$ period.

TABLE II indicates students have used VISIR according to what was expected from the course planning (compulsory use in weeks 1 to 4 , one student per workgroup, in group A), with a small percentage of enthusiastic users, i.e. $4 \%$ of all students that have used VISIR have accessed it more than the double of the expected times. 

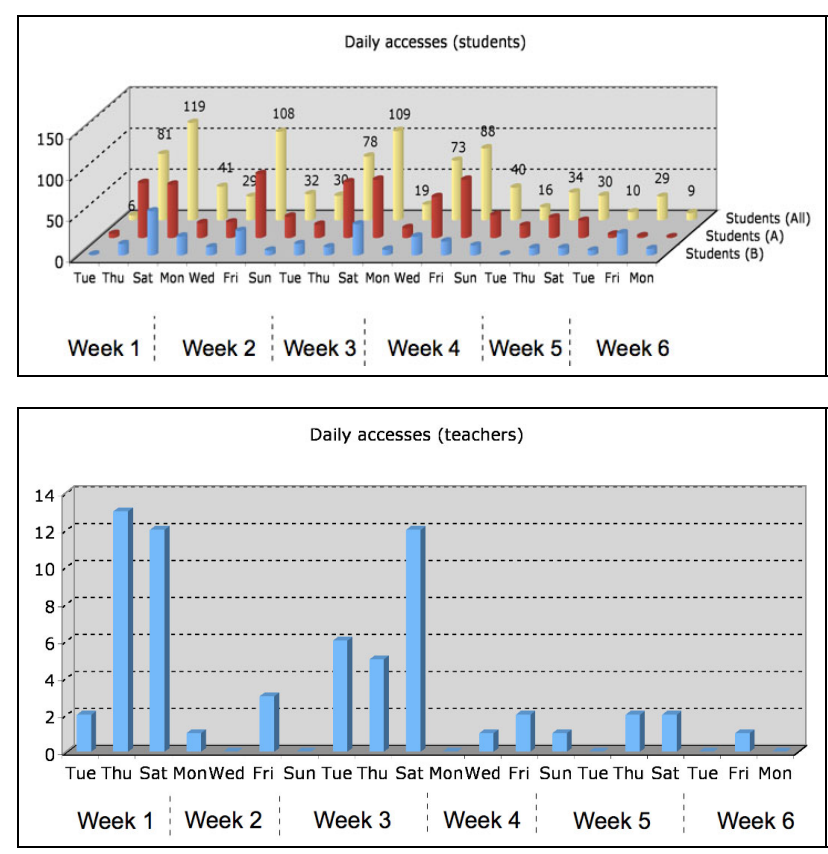

Figure 6. VISIR daily accesses for students (top) and teachers (bottom)

\section{2) Teachers Perceptions}

The course teachers view of this integration and how it influenced the learning development of their students was crucial to better understand its benefits and limitations. All teachers were interviewed and shared their class experience and their perception about students learning concerning VISIR usage. Due to the course planning, VISIR was used along 5 weeks, two for a DC circuit, and the other two for an AC circuit, as explained in section II-B. The initial class of each subject was common for groups A and B (TABLE I). Teachers referred that only some students had their personal computers with them, and that this fact minimized their capability of personally working with it, having a more spectator view of what their colleagues were doing. According to the teachers, especially in group $\mathrm{B}$, this fact prevented a more focused learning development. All teachers agreed that students of group A showed, in general, more laboratory competences in assembling the circuits' components and indeed a much lower percentage of burning multimeter fuses was found (nearly half of the one encountered in previous years).

As to students' knowledge of the subjects, teachers do agree that even though this is more difficult to infer, it is not likely that a greater benefit has been produced. This fact, as teachers emphasize, is due to the lack of time for remotely experimenting different things in order for the students themselves to be able to link those experiments to the concepts developed.

\section{B. On Students' Results}

\section{1) Knowledge and Competence Assessment}

Even though these tests were delivered in class, allowing everyone to participate, we only got 227 matches of the same student pre and pos test, which represents nearly $41 \%$. There were 178 results from group A and 49 from group B. Comparing the results for the total amount of questions (Fig. 7), we can observe that there is a large percentage of students who present positive gains - the majority has gains between $0-40 \%$. These data was treated according to Marx \& Cummings gain lines [12], which means positive gain lines of $20 \%, 40 \%, 60 \%$ and $80 \%$, successively, in the upper left triangle and similar negative gain lines in the lower right triangle. The results are similar if we take only students from group A (Fig. 8), but are slightly improved in group B students (Fig. 9), where the majority has a gain between $20 \%$ and $40 \%$.

As explained in section II, questions addressed different objectives. In order to be able to recognize and identify more clearly those gains, we analyzed these data separately. Figs. 10 to 12 refer only to questions $3 \& 4$, which addressed directly the development of laboratory competences, respectively for both students groups, A and B. The general gains in these two questions are the greatest in all sets of questions delivered. It is once again perceived a similar distribution for the total amount of students and those of group A. Group B shows less problems in handling those questions before and after working with VISIR, not even showing cases of $0 \%$ in the post test (left bottom corner of Fig. 12).

\section{2) Students Perceptions}

A group of students who were identified as enthusiastic users were invited to an interview. They all recognized VISIR as a good instrument to improve their laboratory skills. Some of them compared with their previous experience at the course and stated that it had improved and that this year they understood better the subject due to it.

At the end of the course, students were asked to complete a questionnaire about their perception of the utility VISIR had to their learning and motivation. This was not mandatory, yet 185 students choose to share their opinion, which represents a sample of $33 \%$. As can be seen in TABLE III, students agree that VISIR was most helpful in developing laboratory competences. Even though they did not feel it helped with their motivation, a great percentage would like to extend its usage to other subjects, showing their palatability towards the system. These results also indicate that the system has not shown many irregularities, but students felt that a formal tutorial could have been helpful, as some of them stressed out in the interviews.

\section{3) Course Result}

Our preliminary results show that the students' laboratory report results were improved. Even though this is a positive indicator, a more consistent analysis needs to be done when the students submit themselves to the final examination.

TABLE III.

STUDENTS' PERCEPTION QUESTIONNAIRE RESULTS

\begin{tabular}{|l|l|c|c|}
\hline \multicolumn{2}{|c|}{\begin{tabular}{c} 
Questions \\
Using a Likert scale \\
\multicolumn{2}{|c|}{ (minimum) - 5 (maximum) }
\end{tabular}} & \multicolumn{2}{c|}{ Results } \\
\cline { 3 - 4 } Average & $\begin{array}{l}\text { Standard } \\
\text { Deviation }\end{array}$ \\
\hline \multirow{2}{*}{ Q1 } & $\begin{array}{l}\text { Did VISIR help you on: } \\
\text { a) concepts and problem solving? } \\
\text { b) handing the equiment? } \\
\text { c) Mounting the circuits? }\end{array}$ & 3.40 & 1.07 \\
Q2 & $\begin{array}{l}\text { Did VISIR motivate you to the learning ob- } \\
\text { jectives? }\end{array}$ & 2.77 & 1.22 \\
& \multirow{2}{*}{ Q3 } & a) Provided usage information was sufficient? \\
& b) Was VISIR operating in stable conditions? & 2.61 & 1.20 \\
\hline \multirow{2}{*}{ Q4 } & $\begin{array}{l}\text { Would you like to have similar systems for } \\
\text { other course subjects? }\end{array}$ & 3.66 & 1.10 \\
\hline
\end{tabular}


PAPER

Using VISIR In A LARge UndergRaduATE COURSE: PRELIMINARY ASSESSMENT RESUlts

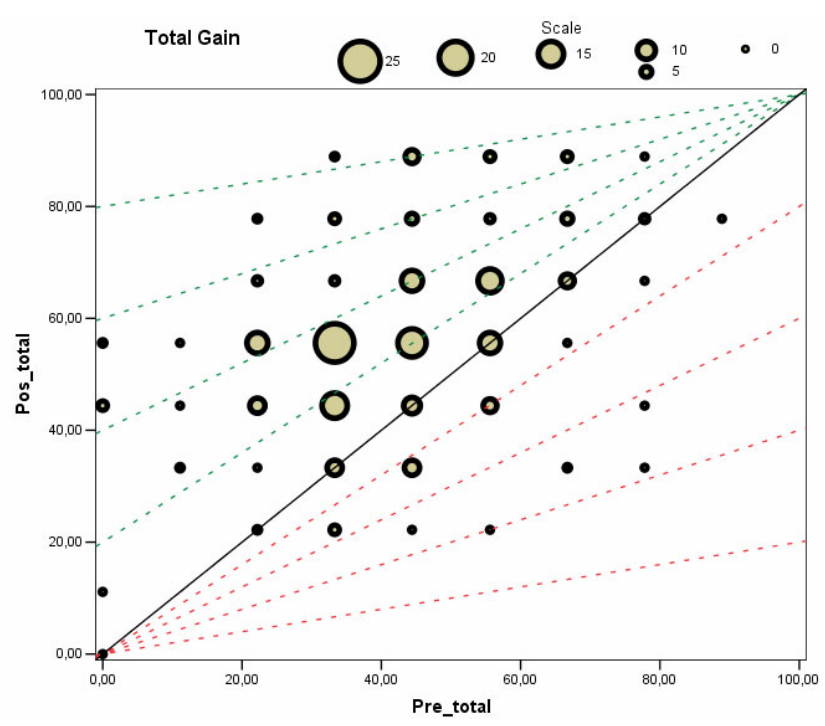

Figure 7. Gain results in the total questionnaire

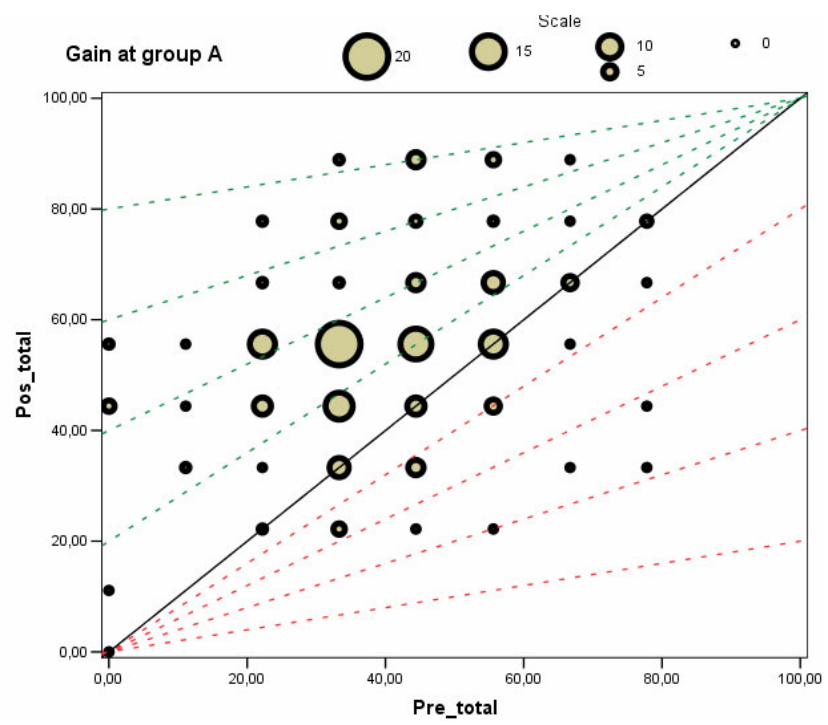

Figure 8. Gain results in the total questionnaire, for group A students

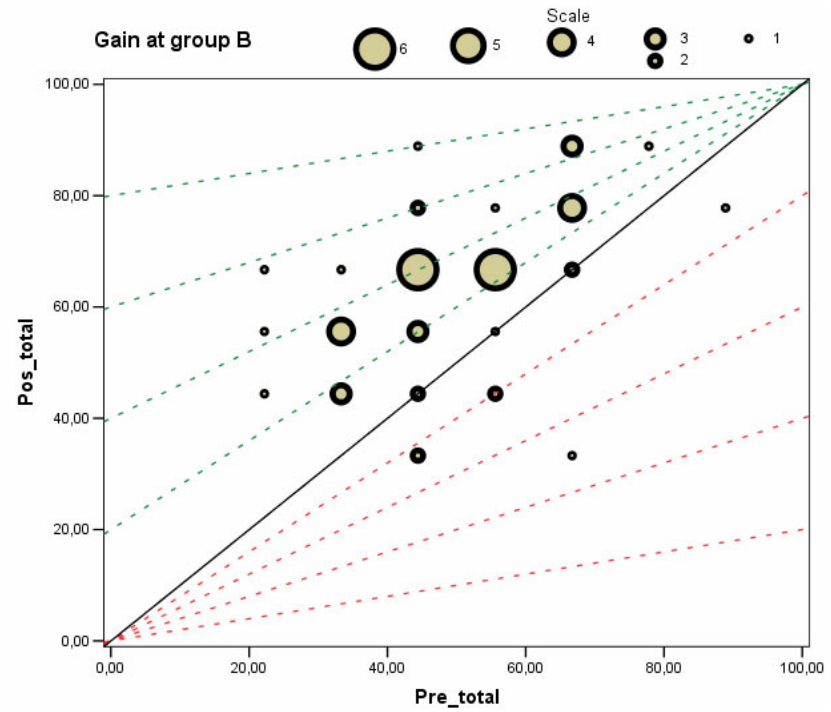

Figure 9. Gain results in the total questionnaire, for group B students

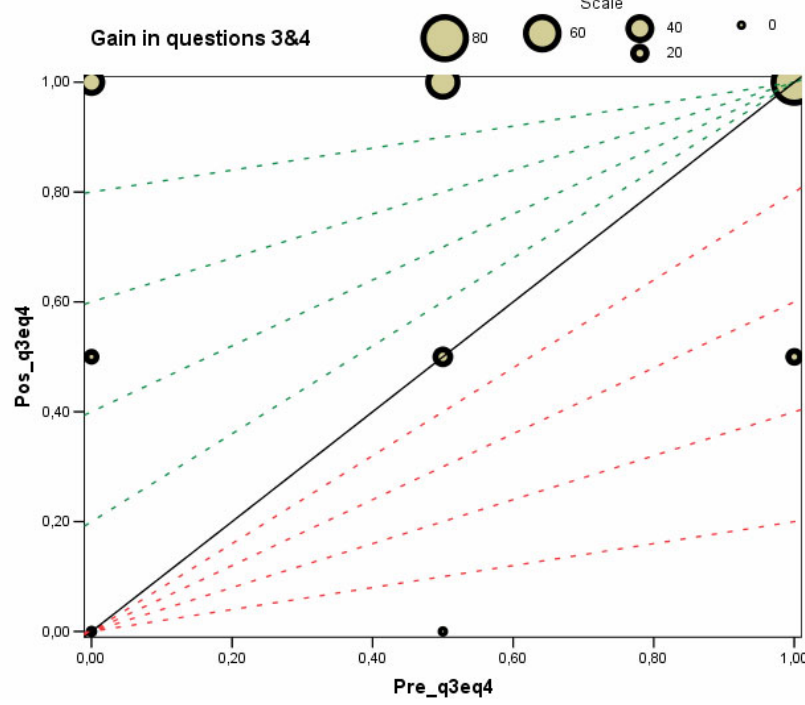

Figure 10. Gain results in questions $3 \& 4$, for both groups of students

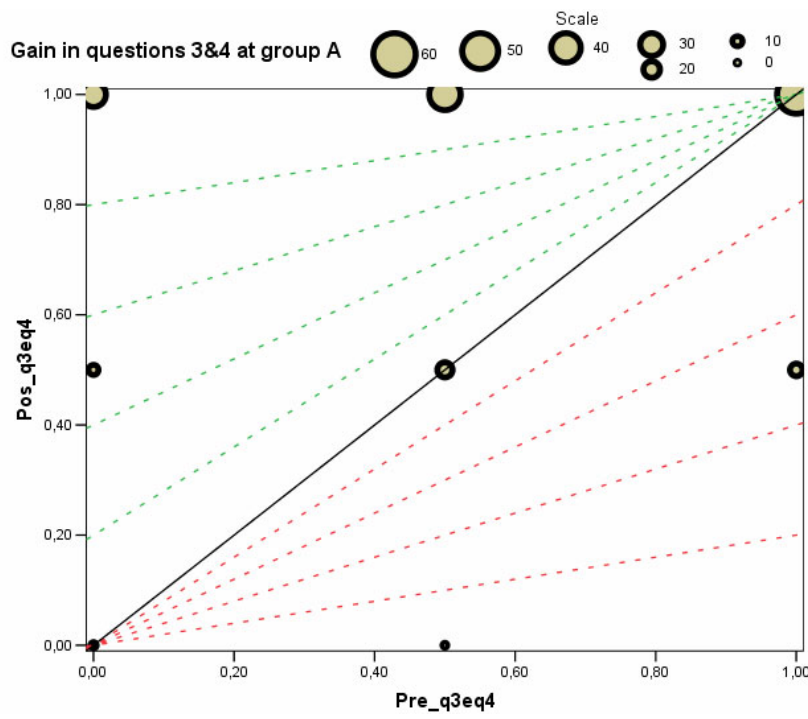

Figure 11. Gain results in questions $3 \& 4$, for group A students

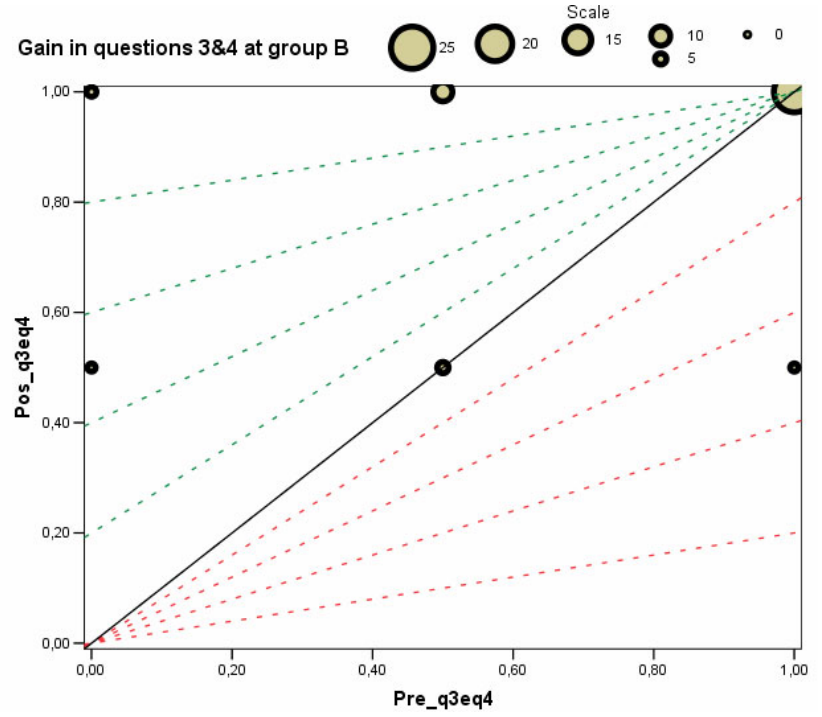

Figure 12. Gain results in questions $3 \& 4$, for group B students 


\section{CONCLUSIONS}

Even though these results are preliminary and a more complete analysis has to be made when the course is complete and students' grades are available, some indicators point to the success of this experience but also lead to the identification of some problems.

Regarding the VISIR usage, the students felt a lack of tutorials. This role was thought to be exclusively from the teacher, when he/she presented VISIR in class, but clearly for the students that was not enough. As to VISIR integration in the Applied Physics course, it became clear that in order to increase the effectiveness of this procedure, these classes should have been taken in a computer room, in order to guarantee every student to really practice with VISIR. Concerning the students learning and development of competences, the majority of students presented gains between $0-40 \%$, and students who simply used VISIR presented similar or better results as those who used VISIR and had laboratory classes, which is in agreement with the other results obtained, but cares of completeness with further results from the course. Finally, our initial belief that VISIR would help students improve their ability in mounting electrical circuits, in hands-on classes, was clearly confirmed by the students' perceptions gathered in the final questionnaire and the teachers' feedback provided during their interviews.

\section{REFERENCES}

[1] Feisel, L. D., \& Rosa, A. J. 2005. The role of the laboratory in undergraduate engineering education. J.Eng. Education, 121-130.

[2] Lindsay, E. D., \& Good, M. C. 2005. Effects of laboratory access modes upon learning outcomes. .IEEE transactions on education, vol. 48, no. 4, pp. 619-631. doi:10.1109/TE.2005.852591

[3] Nickerson, J. V.; Corter, J. E.; Esche, S. K. \& Chassapis, C. 2007. A model for evaluating the effectiveness of remote engineering laboratories and simulations in education. Computers \& Education, Volume 49, no.3, pp. 708-725. doi:10.1016/j.compedu. $\underline{2005.11 .019}$

[4] Ma, J \& Nickerson, J. V. 2006. Hands-On, Simulated, and Remote Laboratories: A Comparative Literature Review. ACM Computing Surveys, vol. 38, no. 3 , article 7.
[5] M Cooper and J. M. M. Ferreira, "Remote laboratories extending access to science and engineering curricular", IEEE Trans. on Learning Tech., vol. 2, pp. 342-353, Oct.-Dec. 2009. doi:10.1109/TLT.2009.43

[6] I Gustavsson, J. Zackrisson, K. Nilsson, J. Garcia-Zubia, L. Håkansson, I. Claesson, and T. Lagö, "A Flexible Electronics Laboratory with Local and Remote Workbenches in a Grid," International Journal of Online Engineering (iJOE), vol. 4, n. ${ }^{0} 2$, pp. 12-16, 2008.

[7] I. Gustavsson et al., "On Objectives of Instructional Laboratories, Individual Assessment, and Use of Collaborative Remote Laboratories," IEEE Trans. on Learning Tech., vol. 2, pp. 263-274, Oct.Dec. 2009. doi:10.1109/TLT.2009.42

[8] N. Hine et al., "Institutional Factors Governing the Deployment of Remote Experiments: Lessons from the REXNET Project," 4th International Conference on Remote Engineering and Virtual Instrumentation (REV'07), Porto, Portugal, June 2007.

[9] I. Gustavsson, "Teacher manual for VISIR," https://openlabs.bth.se/electronics/index.php?page=AboutPage\#, accessed $8^{\text {th }}$ December, 2010.

[10] J. Garcia-Zubia, Hernández, I. Angulo, P. Orduña and J. Irurzun, "Acceptance, Usability and Usefulness of WebLab-Deusto from the Students Point of View", Acceptance, Usability and Usefulness of WebLab-Deusto from Students Point of View, 2009.

[11] A. Hyder, S. K. Choi and D. Schaefer, "Remotely Controlled Laboratory Experiments: Creation and Examples", Proceedings of 2010 IEEE Systems and Information Engineering Design Symposium, University of Virginia, Charlottesville, VA, USA, April 23, 2010.

[12] J. D. Marx and K. Cummings, "Normalized Change", American Journal of Physics, 75(1), pp.87-91, 2007. doi:10.1119/1.2372468

\section{AUTHORS}

Gustavo R. Alves, M. A. Marques, C. Viegas, M. C. Costa Lobo, R. G. Barral, R. J. Couto, F. L. Jacob, C. A. Ramos, G. M. Vilão, D. S. Covita, Joaquim Alves, P. S. Guimarães are with IPP - Polytechnic Institute of Porto, School of Engineering, Porto, Portugal

Ingvar Gustavsson is with BTH - Blekinge Institute of Technology, School of Engineering, Karlskrona, Sweden

Received March $7^{\text {th }}, 2011$. Published as resubmitted by the authors April $20^{\text {th }}, 2011$. 